\title{
PASSADO, PRESENTE E FUTURO DA FORMAÇÃO POR PROJETOS NA COLÔMBIA ${ }^{1}$
}

\section{Carlos David Martínez \\ Ramírez* \\ Carlos Alberto Barón Serrano**}

* Formador de formadores, Instrutor-Pesquisador do Centro Nacional de Hotelaria, Turismo e Alimentação do Serviço Nacional de Aprendizagem (Sena). Psicólogo, Especialista em Psicologia das Organizações, candidato ao Mestrado em Educação pela Universidade Nacional da Colômbia. Bogotá, Bogotá D.C., Colômbia. E-mail: calamar22@misena.edu.co

** Subdiretor do Centro Nacional de Hospitalidade, Turismo e Alimentação do Sena. Zootecnista, Especialista em Gestão Estratégica, MBA, Doutorando em Gestão Educacional pela Universidad de Baja California. Bogotá, Bogotá D.C., Colômbia. E-mail: cbarons@sena. edu.co

Recebido para publicação em 2.10.2018

Aprovado em 13.11.2018

\section{Resumo}

Uma viagem pela história da formação por projetos no Serviço Nacional de Aprendizagem (Sena), uma instituição de formação para o trabalho na Colômbia, associada à educação não formal, técnica, tecnológica e, recentemente, superior. Apresentam-se referências teóricas e se analisa a formação profissional integral, incluindo seus aspectos ontológicos e epistemológicos. A formação por projetos é essencialmente caracterizada por uma abordagem curricular, interdisciplinar, de aplicação e gestão de recursos. Finalmente, o artigo formula o futuro da formação por projetos.

Palavras-chave: Formação. Educação. Projetos. Trabalho.

\section{Introdução}

O Serviço Nacional de Aprendizagem (Sena) é a instituição emblemática de formação para o trabalho na Colômbia. Nasceu em 1957, seguindo o modelo do Serviço Nacional de Aprendizagem Industrial (Senai) do Brasil e programas de formação acelerada da França, entre outros países europeus (MARTíNEZ; NOGUERA; CASTRO, 2003).

Ao longo de sua história, o Sena tem pertencido ao Ministério do Trabalho, embora sua função educacional tenha sido classificada em termos diferentes: educação não formal, educação técnica e tecnológica, formação para o trabalho e desenvolvimento humano e até ensino superior. Como parte da natureza missionária do Sena, a ênfase é frequentemente colocada no desenvolvimento social e técnico dos trabalhadores, na formação profissional integral, na produtividade, na competitividade, na inclusão e no desenvolvimento tecnológico:

O SENA é responsável por cumprir a função do Estado de investir no desenvolvimento social e técnico dos trabalhadores colombianos, 
oferecendo e executando a formação profissional integral, para a incorporação e desenvolvimento de pessoas em atividades produtivas que contribuam para o desenvolvimento social, econômico e tecnológico do país (SENA, 2018).

A trajetória do Sena é tão ampla, que é possível referir-se à formação por projetos percorrendo sua história e até propondo desafios que a instituição enfrentará no futuro próximo. No início, os programas de formação adaptados às necessidades de uma determinada empresa eram chamados de "projetos" - para os quais deve-se considerar que, inicialmente, grande parte dos processos de formação do Sena eram realizados em empresas. Hoje em dia, a instituição dispõe de uma infraestrutura importante, mais de 117 Centros de Formação, para que grande parte da atividade de formação ocorra em sua sede própria. Atualmente, a educação por projetos na instituição é essencialmente caracterizada por uma abordagem curricular, interdisciplinar, de aplicação e gestão de recursos. No futuro imediato, o Sena enfrenta desafios para aplicar a metodologia de formação por projetos com uma abordagem pedagógica, incorporando atividades de pesquisa próprias de sua natureza institucional.

Os programas

\section{de formação}

adaptados às

necessidades de

uma determinada

empresa eram

chamados de

"projetos"
Em 2014, o Sena constituiu a Escola Nacional de Instrutores "Rodolfo Martínez Tono", que depende da Direção de Formação Profissional e gerencia a maioria das orientações e ações de formação, capacitação e desenvolvimento dos instrutores do Sena no âmbito nacional, para o qual desenvolveu atividades de formação em pedagogia, áreas específicas e transversais, bem como pesquisas sobre questões pedagógicas e/ou relacionadas à formação profissional integral desenvolvida pela instituição. Em razão da sua natureza e proximidade com a formação do instrutor, estão surgindo na Escola discussões sobre a pertinência do discurso pedagógico na formação profissional e, entre elas, sobre o impacto da formação por projetos para a formação dos aprendizes.

Na seção seguinte, expõem-se as referências teóricas e contextuais para a formação por projetos em geral e do Sena em particular. Em seguida, discute-se a natureza da educação profissional integral, em outros países, denominada educação terciária ou educação vocacional e treinamento vocacional (VET, de acordo com sua sigla em inglês), incluindo uma análise dos aspectos ontológicos e epistemológicos. Depois, percorre-se sua história e aborda-se a atualidade da formação mediada por projetos na instituição. Finalmente, expõem-se os desafios que podem ser colocados para o futuro próximo da formação por projetos.

\section{Referências teóricas}

No cenário internacional contemporâneo, Amorós (2017, p. 10) observa que as boas práticas na aprendizagem por projetos compartilham três elementos fundamentais:

Convertem os alunos no eixo central de sua própria aprendizagem; desenvolvem modelos de aprendizagem baseados em projetos 
e dinâmicas de Blended Learning; e criam projetos que nascem das próprias necessidades do ambiente, pensando em um impacto global.

O conceito de projeto corre o risco de ser polissêmico. Ele pode ser muito amplo: "primeiro esquema ou plano de qualquer trabalho que às vezes é feito como um teste antes de dar a forma final" (DRAE), dando espaço a quase qualquer protótipo de atividade ou trabalho. Além disso, geralmente é feita uma referência ao termo em diferentes cenários, não apenas no campo educacional, por exemplo: projeto de vida, projeto de lei, projeto produtivo, etc.

No contexto colombiano, é comum referir-se ao quadro lógico dos projetos como ferramenta para articular recursos institucionais e/ou resolver problemas; cada vez mais estão se tornando comuns os estudos de pós-graduação em gestão de projetos e a exigência desse tipo de estudo em instituições do setor público para novos funcionários.

De qualquer forma, no campo educacional, existem tradições que permitem referenciar metodologias de formação por projetos do início do século XX, na América do Norte (Dewey), e de meados do mesmo século, em Londres (Bernstein). Pode-se indicar com maior precisão que:

A metodologia por projetos deve seu desenvolvimento inicial a uma conjunção de ações em diferentes países do mundo, especialmente na Rússia, Alemanha e nos Estados Unidos. Sua origem é atribuída a pesquisadores de diferentes países, [...] historiadores alemães consideram sua atribuição aos professores Charles R. Richards e John Dewey, a partir do trabalho Manual and Industrial Arts Programs, de 1900, enquanto os norte-americanos o atribuem ao perito em agricultura Rufus W. Stimson, a partir de seu trabalho Home Project Plan de 1908, mas como o grande promotor do educador William H. Kilpatrick, fundamentado em Stimson (CIRO ARISTIZIBAL, 2012, p. 14, nota do autor).

Atualmente, parecem existir coincidências com relação aos objetivos identificados para a Aprendizagem Baseada em Projetos:

- Formar pessoas capazes de interpretar os fenômenos e os acontecimentos que ocorrem ao seu redor.

- Desenvolver a motivação para a busca e a produção de conhecimentos, uma vez que, por meio de experiências de aprendizagem atraentes, que envolvem os alunos em projetos complexos e reais, desenvolvem-se e aplicam-se habilidades e conhecimentos (CHILE, 2015).

No contexto colombiano, há autores que concordam em apontar, entre os benefícios da Aprendizagem Baseada em Projetos, a integração de disciplinas, apoiadas em atividades de pesquisa documentadas, como é o caso da pesquisa desenvolvida pela Universidade Nacional da Colômbia (JURADO et al, 2011). 
Outros benefícios da Aprendizagem Baseada em Projetos têm a ver com:

- Organizar atividades em torno de um objetivo comum, definido pelos interesses dos alunos e com o compromisso adquirido por eles.

- Fomentar a criatividade, a responsabilidade individual, o trabalho colaborativo, a capacidade crítica, a tomada de decisões, a eficiência e a facilidade de expressar suas opiniões pessoais.

- Que os alunos vivenciem as formas de interação exigidas pelo mundo atual.

- Combinar positivamente a aprendizagem de conteúdos fundamentais e o desenvolvimento de habilidades que aumentem a autonomia no aprender.

- O desenvolvimento da pessoa; os alunos adquirem a experiência e o espírito de trabalho em grupo, à medida que estão em contato com o projeto.

- Desenvolver habilidades sociais relacionadas ao trabalho em grupo e negociação, planejamento, condução, monitoramento e avaliação de suas próprias habilidades intelectuais, incluindo a resolução de problemas e a realização de julgamentos de valor.

- Satisfazer uma necessidade social, que fortalece os valores e o compromisso do aluno com o ambiente ao redor (CHILE, 2015).

O pesquisador Michael Knoll argumenta que essa questão, em termos históricos, tem sido tratada com superficialidade, e considera que essa metodologia não era produto do movimento industrial progressista na educação que surgiu nos Estados Unidos no fim do século XIX, mas que seu primeiro uso remonta ao século XVI (CIRO ARISTIZIBAL, 2012, p. 14). Para essa análise, propõem-se cinco períodos históricos para recapitular a história da formação por projetos:

1. 1590-1765: início dos trabalhos por projetos em escolas de arquitetura na Europa (na Academia de San Lucas, em Roma, Academia de Belas Artes);

2. 1765-1880: o projeto como ferramenta comum de aprendizagem e sua migração para a América;

3. 1880-1915: trabalho por projetos na instrução manual e em escolas públicas;

4. 1915-1965: redefinição do método de projetos e sua migração de volta à Europa;

5. 1965-dias atuais: redescoberta da filosofia por projetos e a terceira onda de expansão internacional (CIRO ARISTIZIBAL, 2012, p. 15). 
Além disso, de acordo com Ciro, vale notar que a Aprendizagem Baseada em Projetos surge de uma abordagem construtivista, que progrediu a partir dos trabaIhos de psicólogos e educadores como Lev Vygotsky, Jerome Bruner, Jean Piaget e John Dewey:

Deve-se levar em conta que o movimento construtivista, que busca fornecer ao aluno ferramentas que possibilitem a geração e modificação de ideias para desenvolver seus próprios conhecimentos, foi o que direcionou a visão das metodologias de ensino para a aprendizagem como processo ativo do indivíduo. Esse pensamento construtivista teve grandes contribuições nos avanços educacionais, o que permitiu abandonar o método tradicional como metodologia soberana, e teve em seus desenvolvimentos uma aplicação em direção ao que foi chamado de aprendizagem por projetos, derivado que foi desenvolvido precisamente por William Heard Kilpatrick.

Kilpatrick, no início do século XX, dentro do chamado movimento progressista americano, levantou o método de projetos como o primeiro modelo pedagógico baseado na experiência empírica apoiada pelas teorias de John Dewey, levantadas no fim do século XIX. Esta proposta baseia-se na experimentação científica, adotando interesses espontâneos no aluno para potencializar sua atuação dentro do marco de autonomia e solidariedade. A prática educativa do pragmatismo pedagógico materializou-se no Project Method, inspirado por Dewey e formulado em 1918 por seu discípulo Kilpatrick. Sua aplicação foi iniciada na Universidade de Columbia em Nova York em 1918, mas teve pouca popularidade nos Estados Unidos. Logo em seguida, foi esquecido e redescoberto apenas na década de 1970, quando a ideia do método de projeto foi novamente levantada, mas juntamente com uma concepção de um currículo aberto e uma educação comunitária (CIRO ARISTIZIBAL, 2012, p. 16).

Atualmente, existem definições de projetos como estratégias de pesquisa que permitem flexibilidade didática, respondendo às necessidades do ambiente:

Um projeto é uma investigação profunda de uma tarefa/problema; seu desenvolvimento gera um grande número de ações que demandam um uso responsável do tempo de trabalho autônomo. Nos projetos de formação os problemas atuam como elementos integradores do conhecimento, tornando a oferta de formação mais personalizada e flexível, pois, como disse Garrik, a flexibilidade pedagógica pode ser entendida como uma amplitude de aprendizado que se traduz em oportunidades para realizá-la. Assim, a flexibilidade pedagógica, realizada por meio de projetos, torna-se o cenário ideal que produz diversos contextos de aprendizagem, que favorecem novas formas de interação e possibilitam uma grande variedade de competências (AMORÓS, 2017, p. 12). 


\section{A natureza da formação profissional integral}

Às vezes, é importante diferenciar educação formal e não formal; na literatura, podem ser encontradas diferenças em termos de escolarização e não escolarização; nas ciências sociais, é possível diferenciar socialização (comum na sociologia), endoculturação (recorrente na antropologia) e aprendizagem (frequente na psicologia). Para alguns intelectuais, o conceito de formação é mais amplo que o conceito de educação (pode-se pensar no conceito kantiano de forma-

Para alguns intelectuais, o conceito de formação é mais amplo que o conceito de educação ção do adulto), enquanto outros pensam que o conceito de educação é mais amplo e envolve diferentes cenários (não apenas os de escolarização formal).

No caso da Colômbia, os conceitos de formação e instrução na segunda metade do século XX costumam estar associados a processos educacionais no contexto laboral, embora, na Constituição Política Nacional de 1991, seja usado o termo formação e, no início do século XX, a entidade governamental encarregada dos processos formais de educação fosse chamada de Ministério da Educação - atualmente se denomina Ministério da Educação Nacional (MEN).

Há concordância de que, na América Latina, os processos de formação para o trabalho têm uma história paralela, às vezes distante, dos processos de educação acadêmica tradicional. De qualquer forma, atualmente, em diferentes regiões do planeta, as diferenças entre a formação para o trabalho e a educação formal são confusas (VELDE, 1999).

Com essas referências, é interessante rever a ontologia institucional (a natureza do Sena) para localizar os fundamentos epistemológicos da formação profissional integral (a natureza do conhecimento manipulado). Embora o Sena tenha pertencido ao Ministério do Trabalho, inicialmente a categorização de seu processo de formação era a educação não formal, em seguida a formação técnica e tecnológica, e agora a formação para o trabalho e o desenvolvimento humano (programas de nível técnico) e ensino superior (programas de nível tecnológico).

Na última década, as exigências de cadastro qualificado pelo MEN para atender às exigências dos programas de nível tecnólogo geraram questionamentos dentro da instituição. Para alguns, é um risco que pode desvirtuar a natureza vocacional do Sena para uma natureza de cunho acadêmico, como o que se espera encontrar no estereótipo da universidade média:

Enquanto alguns funcionários, dentro da entidade, interpretam que o Sena não está pronto para ser classificado como uma universidade e que sua ênfase no 'trabalho' não deve ser mudada para uma ênfase no 'acadêmico', outros concordam que em última análise se desenvolve uma função educativa que lhe permite fazer parte da educação formal e do ensino superior (MARTíNEZ RAMÍREZ, 2015, p. 56). 
No contexto da técnica e da tecnologia, para Mario Bunge, as investigações científicas buscam o entendimento das relações de causa e efeito, enquanto no conhecimento tecnológico, o principal é analisar e desenvolver os efeitos e depois estudar as causas. Essa ideia pode ajudar a refletir sobre a natureza do conhecimento de acordo com sua direção e funcionalidade.

O Sena se constitui seguindo o esquema do Senai, do Brasil, e práticas inspiradas nos esquemas de formação acelerada de alguns países europeus. Existem vários discursos em torno da criação do Sena. Para sua compreensão, é importante identificar o contexto histórico internacional e local.

Na segunda metade do século XX, houve importantes mudanças na consolidação da ordem econômica e geopolítica em nível internacional:

Após a Segunda Guerra Mundial, em 1945, a humanidade teve que se reajustar a outra situação. A indústria militar desacelerou seu ritmo de produção e a indústria manufatureira reconsiderou suas metas e partiu em busca de novos mercados. Os países pequenos - atrasados, como eram chamados - iniciaram uma era de ajustes para adequarem-se a diferentes circunstâncias. A conflagração universal deixou uma terrível sequela de destruição e desastre, mas para se desenvolver os equipamentos militares mais formidáveis até então conhecidos, foram descobertos tecnologias e sistemas que mudaram as regras do jogo econômico em todo o mundo (QUIROZ DE ARENA, 1978, p. 7).

Assim, na educação da segunda metade do século XX, importantes mudanças foram concebidas, que marcaram a noção da educação e sua função. A educação passa a ser concebida como um bem de consumo e não apenas como um luxo de poucas elites. Em grande parte dos países desenvolvidos, uma educação para a emancipação é visualizada e espera-se que haja transferência de tecnologia para os países pobres (SCHUMACHER, 1983).

Nos propósitos iniciais do Sena, há várias histórias que convergem. Por um lado, há a versão que destaca a luta dos trabalhadores colombianos para exigir do governo benefícios sociais e capacitação (na Colômbia, o Sena e as agências de fomento nasceram na mesma época); nessa versão da história, são relevantes: os esforços dos trabalhadores reivindicando melhores condições, a igreja apoiando a noção de bem-estar da família, e os empresários concordando em facilitar ou colaborar no processo. Há outra versão do nascimento do Sena que destaca o trabalho de seu fundador, Rodolfo Martínez Tono, por ter a visão e liderar os primeiros grandes esforços para a criação e expansão da entidade, em consonância com a necessidade de qualificação dos trabalhadores do país. Existe até uma versão sobre a criação do Sena que destaca o contexto internacional:

O SENA foi um dos primeiros projetos por meio dos quais o Programa das Nações Unidas para o Desenvolvimento (PNUD) iniciou suas atividades na Colômbia. Em 1959, o programa ampliado de assistência técnica, depois de assessorar e financiar dois projetos 
no período de 1950 a 1954, aprovou dois projetos em dezembro de 1959: um correspondia ao treinamento vocacional do SENA e outro se referia ao reconhecimento pedológico da parte norte das planícies orientais (MARTÍNEZ, NOGUERA, CASTRO, 2003, p. 47).

Em outros países da América e da Europa, refere-se ao tipo de educação desenvolvido pelo Sena como VET ou ensino superior. No caso da Colômbia, a falta de articulação do sistema educacional dificultou que vários setores da comunidade acadêmica do Sena aceitassem o conceito de educação superior para a função do Sena.

Os fundamentos epistemológicos da formação profissional integral não são alheios às características ontológicas, políticas e econômicas da instituição. As diferenças entre uma abordagem acadêmico-científica e outra de natureza trabalhista-tecnológica podem determinar o horizonte que o conhecimento e as características dos projetos desenvolvidos na instituição podem ter.

\section{A história da formação por projetos: passado e presente}

As primeiras décadas do Sena referiram-se à estruturação de projetos para identificar os programas de formação desenvolvidos para responder à necessidade de formação de uma empresa ou de uma organização específica, o que constituiu uma das primeiras formas de formação por projetos, não só pela denominação, mas pela atenção a uma real necessidade do ambiente de trabalho. Na década de 1980, essa ideia foi mais formalmente sofisticada, por meio do Acordo n. 12 de 1985 (SENA, 1985), no qual o projeto é definido como instrumento de gestão, que prevê e organiza ações de planejamento, técnico-pedagógicas e de administração, a fim de solucionar uma necessidade da sociedade, enquadrada nos objetivos e nas políticas da entidade. É o instrumento que concretiza a estruturação da resposta para atender às necessidades da população, de acordo com o Artigo 13, na Unidade Técnica do Sena (1985). Dessa forma, os aspectos técnico-pedagógicos e de gestão de recursos são combinados na concepção dos projetos, de modo que os aspectos administrativos e pedagógicos se entrelaçam com uma perspectiva sistêmica.

O modelo de Formação por Projetos do SENA implica toda uma extensão do raio de ação pedagógico dessa metodologia, indo além dos cenários de aplicação tradicionais para criar novos ambientes de aprendizagem, tanto em suas próprias instalações como nas empresas e nos locais onde os alunos moram e trabalham, priorizando as necessidades e demandas econômicas e sociais do meio ambiente. O referido modelo por projetos foi desenvolvido para desenvolver uma medida de gestão dos Centros, que integra variáveis organizacionais e técnico-pedagógicas (relacionadas à gestão do centro, aspectos materiais, pedagógicos, didáticos etc.) (AMORÓs, 2017, p. 14). 
Vale ressaltar a ênfase administrativa dada às primeiras concepções do projeto no Sena. Por exemplo, no Artigo 15 do Acordo n. 12 de 1985, afirma-se que um projeto é constituído em unidades de: "Programação, Administração, Execução, Orçamento e Custos, Avaliação"; no Artigo 16 desse mesmo Acordo, afirma-se que "a Formação Profissional Integral contempla em suas fases os processos administrativos que garantam o fornecimento e a organização eficientes e oportunos de recursos humanos, físicos e financeiros". Dessa forma, embora os chamados aspectos técnico-pedagógicos sejam incorporados, a ênfase continua a ser acentuada em questões administrativas.

Alguns exemplos do espírito de formação por projetos no início do Sena, no sentido de desenvolver aplicações práticas em ambientes reais de trabalho, aplicando também conceitos de integralidade e interdisciplinaridade, incluindo o trabalho comunitário, são as seguintes iniciativas:

- O Programa de Promoção Profissional Popular Rural (PPPR), especialmente no início da década de 1970.

- O Programa de Promoção Profissional Popular Urbana (PPPU), desde o fim da década de 1960, mas com força desde 1970.

- Os Programas Móveis, especialmente depois de 1974.

- A Capacitação Empresarial Campesina (CEC), também desde a década de 1970.

- Os Laboratórios Experimentais de Organização Socioempresarial (LEOS), documentados desde 1976.

- A Capacitação para a Participação Campesina (Capaca), também desde a década de 1970.

- A Capacitação para a Integração e Participação Comunitária Urbana (Cipacu), desde meados da década de 1980.

- O Sena Comunitário, também desde meados da década de 1980.

- O Jovens Rurais, desde o ano de 2003.

A ênfase nessas estratégias de formação por projetos era principalmente conseguir uma cobertura significativa, especialmente para populações localizadas em áreas periféricas ou com certos tipos de vulnerabilidade, de forma que os objetivos estratégicos fossem combinados com ferramentas pedagógicas. No caso particular dos LEOS, a ênfase no uso de ferramentas pedagógicas com atividades de experimentação e simulação era mais clara.

Dessa forma, pode-se identificar como o Sena tem desenvolvido esforços para responder às necessidades históricas e territoriais de formação profissional integral, por exemplo, nas suas primeiras décadas, adaptando-se aos requisitos nacionais para atingir os setores rurais, periféricos e os mais isolados das grandes capitais. 
Na primeira década do século XXI, com a influência das tendências europeias e da Organização das Nações Unidas para a Educação, a Ciência e a Cultura (Unesco), propagam-se discursos que ressaltam a importância da aprendizagem ao longo da vida, a interdisciplinaridade, a importância da inovação na aplicação das didáticas ativas, a relevância da formação de acordo com as mudanças nos ambientes de trabalho e tecnológico, etc. Assim, dá-se um novo significado aos projetos de formação no Sena, procurando enfatizar os aspectos pedagógicos da metodologia de aprendizagem por projetos. Dessa maneira, o novo sentido atribuído aos projetos envolve a geração de conhecimentos, em vez de privilegiar apenas os aspectos empresariais, embora também permita considerar os ambientes de trabalho como referência pedagógica para simular cenários do mundo do trabalho nos processos de ensino-aprendizagem-avaliação.

O novo sentido atribuído aos projetos envolve a geração de conhecimentos
Precisamente no início do século XXI, é estabelecida uma diferença no Sena entre projetos "produtivos", que enfatizam os aspectos de empreendimento e empreendedorismo, projetos "formativos", que se concentram na geração de conhecimento, e projetos "produtivo-formativos", que integram esses dois horizontes anteriores.

De acordo com Amorós (2017, p. 14-15), o Sena adotou a formação por projetos como a principal estratégia para o desenvolvimento de competências, "visto a partir de uma perspectiva metodologicamente integrativa, que entende os projetos como a base das atividades de formação propostas aos aprendizes, em um programa de formação que também incorpora outras técnicas didáticas como complemento".

Em 2007, a instituição estabelece um marco conceitual e pedagógico para a implementação da formação por projetos no Sena, no qual são identificados como principais aspectos: as competências laborais (genéricas e transversais); princípios de aprendizagem, como a dimensão tácita do conhecimento, a aprendizagem baseada em problemas, a construção de significados, a aprendizagem significativa, a metacognição e a autorregulação; e também alguns princípios didáticos, como ausência de substituição, antecipação ou menor defasagem, motivação, individualização, socialidade, interdisciplinaridade temática, diversidade metodológica, interfuncionalidade psíquica, homogeneidade preditiva, reciprocidade dinâmica teórico-prática, explicitação crítico-construtiva e criatividade (SENA, 2007, p. 37-50).

Na primeira década do século XXI, a ênfase é colocada na formação por projetos como uma oportunidade para simular ambientes reais de trabalho nos ambientes de formação; assim, vários tipos de projetos de infraestrutura são promovidos para simular ambientes reais de produção nos ambientes de formação da instituição.

Atualmente, espera-se que a formação por projetos permita: o desenvolvimento de atividades teórico-práticas, a integração curricular, a personalização dos processos de formação (rota de aprendizagem é um nome dado a um conjunto de projetos que compõem um programa de formação, que podem variar de acordo com as 
necessidades e características de cada aprendiz), a integração da abordagem de competências, o desenvolvimento de projetos produtivos e a aquisição (e geração) de conhecimentos.

Para ilustrar de que maneira a formação por projetos é atualmente aplicada no Sena, de maneira sintética, pode-se relacionar dois tipos de práticas: aquelas sugeridas na literatura institucional disponível (práticas discursivas) e a maneira como são comumente assimiladas e implementadas as ações específicas nos ambientes de formação (práticas não discursivas).

Quanto às práticas discursivas, a metodologia deve permitir processos de personalização, respeitando os ritmos e estilos de aprendizagem, para os quais é possível diversificar os projetos de formação em um grupo de aprendizes, de acordo com as diferenças individuais; dessa forma, diferentes rotas de aprendizagem poderiam ser desenvolvidas dentro de um grupo (de modo que cada rota contivesse um conjunto diferente de projetos), facilitando a personalização dos processos de ensino-aprendizagem-avaliação.

Os procedimentos também estabelecem que os projetos podem ser definidos pelos aprendizes no início do processo de formação. Na aplicação diária, as políticas de extensão de cobertura e o perfil de ingresso dos aprendizes tornam complexa a real aplicação desses procedimentos. Na figura a seguir, resume-se o esquema exposto.

\section{Figura 1 - Práticas discursivas na aplicação da formação por projetos no Sena}

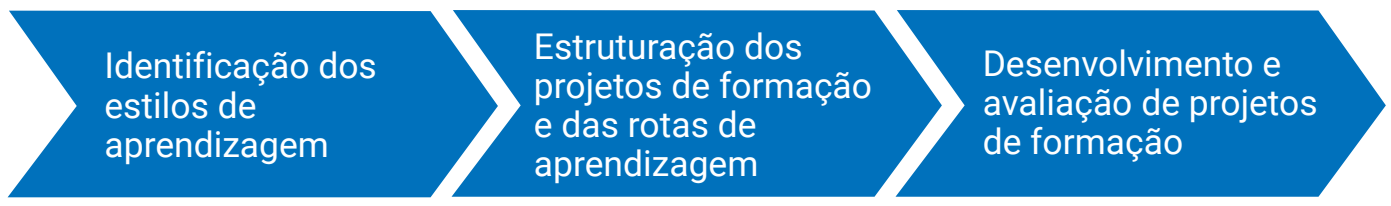

Fonte: Elaboração própria.

Em práticas não discursivas, é comum enfatizar uma perspectiva curricular, de modo que as estruturas curriculares (planos de estudo) são geralmente relacionadas a atividades de projeto orientadas para aplicações no campo ou projetadas para integrar diversos conteúdos. A figura a seguir sintetiza esse esquema.

Figura 2 - Práticas não discursivas na aplicação da formação por projetos no Sena

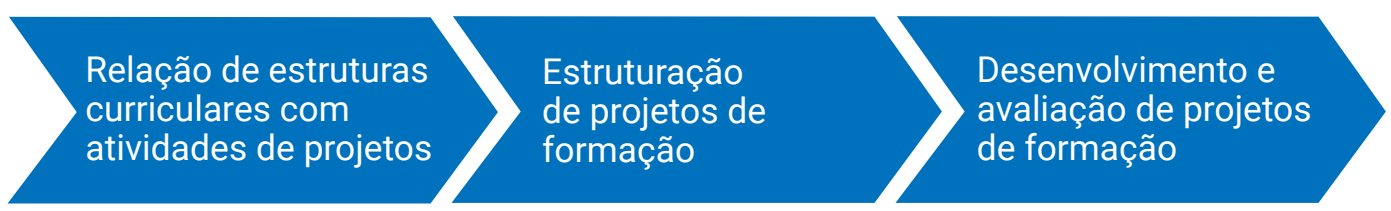

Fonte: Elaboração própria. 
Uma vantagem interessante nas práticas discursivas tem a ver com o potencial de personalização dos processos de ensino-aprendizagem-avaliação; uma desvantagem estaria associada à limitação da experiência por privilegiar um estilo de aprendizagem particular ou à aplicação limitada da diversificação de projetos (uma vez que impõe limitações administrativas para sua operação).

Algumas vantagens identificáveis em práticas não discursivas têm a ver com o potencial dos projetos de formação para desenvolver aplicações em ambientes reais de trabalho e para a solução de problemas tecnológicos ou empresariais; uma desvantagem teria a ver com a limitação da experiência quando se propõem atividades de aprendizagem que são muito genéricas (para facilitar a integração curricular) ou muito específicas (limitadas a um único contexto ou a um único processo).

O quadro a seguir resume algumas das vantagens e desvantagens das práticas discursivas e não discursivas associadas à formação por projetos no Sena na última década.

Quadro 1 - Vantagens e desvantagens das práticas discursivas e não discursivas associadas à formação por projetos no Sena

\begin{tabular}{|l|l|l|}
\hline Vantagens & Práticas discursivas & Práticas não discursivas \\
\hline & $\begin{array}{l}\text { Personalização dos processos de ensino- } \\
\text { aprendizagem-avaliação. } \\
\text { Integração de atividades para o } \\
\text { empreendimento e o empreendedorismo e } \\
\text { para a geração de conhecimento e pesquisa. }\end{array}$ & $\begin{array}{l}\text { Aplicações em ambientes } \\
\text { reais de trabalho e para } \\
\text { a solução de problemas } \\
\text { tecnológicos ou em } \\
\text { contextos empresariais. }\end{array}$ \\
\hline Desvantagens & $\begin{array}{l}\text { Limitação da experiência por privilegiar um } \\
\text { determinado estilo de aprendizagem. }\end{array}$ & $\begin{array}{l}\text { Limitação da } \\
\text { experiência quando se } \\
\text { propõem atividades de } \\
\text { aprendizagem que são } \\
\text { muito genéricas ou muito } \\
\text { específicas. }\end{array}$ \\
\hline
\end{tabular}

Fonte: Elaboração própria.

Alguns casos recentes de sucesso na aplicação da formação por projetos no Sena incluem o desenvolvimento de abordagens investigativas (VARGAS PARGA, 2016), a simulação de ambientes empresariais (BONILLA CELY, 2016; RINCÓN TRUJILLO, 2016), ações de combate ao desemprego (HENAO PUERTA, BOLAÑOS BETANCOURT, 2016), a inclusão de populações afro-colombianas (AGRONO MORALES et al., 2016) e populações com deficiências cognitivas (FLÓREZ LOZANO, 2016, MALAGÓN; ACUÑA; MARTÍNEZ, 2018), a inovação e a descentralização de recursos (ALDANA VALDÉS, 2016) e a aplicação da matemática no contexto (BORJA MONTÑA, 2016), entre outros casos que foram recentemente documentados, graças, em grande parte, ao apoio e aos esforços editoriais da Escola Nacional de Instrutores "Rodolfo Martínez Tono". 


\section{Os desafios do treinamento por projetos: o futuro}

É importante gerar espaços de reflexão para entender o cenário atual e os horizontes de melhoria. Segundo Amorós (2017, p. 11), é possível afirmar que a Aprendizagem Baseada em Projetos amplia o conhecimento dos alunos e desenvolve suas habilidades para torná-los mais competentes, "mas para isso é preciso uma profunda reflexão didática que ajude a definir 'o que' queremos ensinar, 'por que' vamos ensinar e, acima de tudo, 'como' vamos ensinar".

\section{É importante} gerar espaços de reflexão para entender 0 cenário atual e os horizontes de melhoria
Uma situação paradoxal recente no campo educacional em geral é enfatizar a melhoria das políticas de cobertura que obtiveram resultados interessantes nesse campo, sob o risco de negligenciar a qualidade da educação. Embora as políticas para aumentar a cobertura tenham apresentado resultados relevantes, deve-se priorizar estratégias que não aumentem o número de alunos por sala de aula; é mais fácil personalizar os processos educacionais usando a Aprendizagem Baseada em Projetos quando um grupo de aprendizes oscila entre 7 e 14 participantes, ou até mesmo um número próximo de 25 ou 30 é razoável (a diversificação dos projetos seria administrativamente viável), ao contrário de quando se tem mais de 40 aprendizes por sala de aula (oficina, laboratório ou ambiente de formação).

\section{Considerações finais}

O Sena conta com experiências bem-sucedidas na aplicação da formação por projetos, tais como: o desenvolvimento de projetos produtivos baseados no aproveitamento dos recursos dos Centros de Formação; a integração de recursos de vários Centros de Formação para o desenvolvimento de projetos que tenham sido denominados intercentros; a integração de projetos para a geração de conhecimento e, ao mesmo tempo, para o desenvolvimento de atividades de empreendimento ou empreendedorismo.

Uma conclusão importante é que a incorporação de métodos de Aprendizagem Baseados em Projetos pode ser assumida como um desafio para o futuro próximo, enfatizando os aspectos pedagógicos com uma visão focada no sujeito aprendiz e no sujeito instrutor, superando a tradição de enfatizar os aspectos curriculares e administrativos (sem desconsiderar sua importância).

Outro desafio interessante é incorporar com maior precisão o desenvolvimento de projetos de pesquisa na formação de competências laborais, dando lugar à criação de linhas de pesquisa que favoreçam a integração de atividades de pesquisa relevantes para e com os setores produtivos e tecnológicos que impactam a instituição, reconhecendo sua natureza missionária e abrindo espaço para pesquisas em Pedagogia e educação em geral.

Percorrendo-se a história da formação por projetos é possível visualizar a própria história dos movimentos pedagógicos na instituição, sua natureza institucional e 
epistemológica. Para fazer uma prospecção adequada da formação por projetos no Sena, é importante reconhecer sua história para aplicar desenvolvimentos inovadores, que respeitem as características próprias da educação profissional integral.

A Escola Nacional de Instrutores, nos últimos anos, tem gerado importantes debates sobre a abordagem pedagógica dos projetos de formação. Em termos gerais, tem-se buscado melhorar o enriquecimento das experiências pedagógicas; em termos operacionais, a viabilidade da diversificação de projetos de formação tem sido discutida para que um programa de formação disponha de uma ampla gama de projetos de formação que possam potencializar a aprendizagem significativa e a geração de conhecimento, sem obscurecer a natureza da formação para o trabalho que historicamente caracterizou a instituição.

Em termos teóricos, é necessário gerar debates e reflexões sobre o potencial dos projetos de formação para garantir o enriquecimento da experiência pedagógica e avaliar o seu impacto real, o envolvimento de atividades de pesquisa, bem como uma perspectiva que contextualize a estratégia com uma abordagem mais ampla envolvendo a aprendizagem baseada em problemas, transcendendo a perspectiva tradicionalmente aplicada, focada nos aspectos administrativos, pragmáticos e empresariais, sem perder a natureza institucional no horizonte.

\section{Nota}

1 O presente artigo foi formulado com o acompanhamento da Escola Nacional de Instrutores "Rodolfo Martínez Tono" da Direção de Formação, do Serviço Nacional de Aprendizagem (Sena), da Colômbia.

\section{Referências}

AGRONO MORALES, S. et al. Inclusión educativa en poblaciones afrocolombianas, propuesta pedagógica para la paz. Rutas de Formación: prácticas y experiencias, Bogotá, n. 2, p. 39-47, jan./jun. 2016.

ALDANA VALDÉS, E. La prioridad en educación terciaria: el caso innovar en el departamento del Tolima. Rutas de Formación: prácticas y experiencias, Bogotá, n. 3, p. 15-21, jan./dez. 2016.

AMORÓS, A. Los desafíos didáctico-pedagógicos de la educación técnica: formación profesional del siglo XXI. Rutas de Formación: prácticas y experiencias, Bogotá, n. 5, p. 9-15, jul./dez. 2017.

BONILLA CELY, S. M. Modelo de gestión y transferencia de conocimiento para promover la estrategia pedagógica de empresas simuladas. Rutas de Formación: prácticas y experiencias, Bogotá, n. 2, p. 64-69, jan./jun. 2016. 
BORJA MONTÑA, D. F. Propuesta pedagógica: matemáticas en contexto. Rutas de Formación: prácticas y experiencias, Bogotá, n. 3, p. 60-67, jul./dez. 2016.

CHILE. Congreso Nacional. Biblioteca. Departamento de Servicios Legislativos y Documentales. Aprendizaje basado proyectos: torneo delibera. Santiago de Chile, 2015. Disponível em: <https://www.bcn.cl/ obtienearchivo?id=documentos/10221.1/55744/1/Aprendizaje\%20basado\%20 en\%20proyectos.pdf>. Acesso em: nov. 2018.

\section{CIRO ARISTIZIBAL, C. Aprendizaje basado en proyectos (A.B.Pr) como} estrategia de enseñanza y aprendizaje en la educación básica y media. Medellín: Universidad Nacional de Colombia, 2012. Disponível em: <http://www.bdigital.unal. edu.co/9212/1/43253404.2013.pdf>. Acesso em: nov. 2018.

FLÓREZ LOZANO, M. N. Desafíos en la práctica docente para la inclusión educativa y laboral de personas con discapacidad cognitiva: una experiencia en el marco de la Formación Profesional Integral. Rutas de Formación: prácticas y experiencias, Bogotá, n. 2, p. 54-59, jan./jun. 2016.

HENAO PUERTA, A.; BOLAÑOS BETANCOURT, C. X. Formación Sena para contrarrestar desempleo en la industria de la caña de azúcar. Rutas de Formación: prácticas y experiencias, Bogotá, n. 2, p. 32-37, jan./jun. 2016.

JURADO, F. et al. Hacia la integración curricular: el enfoque por ciclos en la escuela. Bogotá: Universidad Nacional de Colombia, 2011.

MALAGÓN, R.; ACUÑA, S.; MARTÍNEZ, C. D. Inclusión educativa en la formación profesional: el caso del Centro Nacional de Hotelería Turismo y Alimentos en el Sena Colombia. Revista Inclusiones: revista de humanidades y ciencias sociales, Santiago do Chile, v. 5, p. 19-25, 2018. Número especial.

MARTÍNEZ BOOM, A.; NOGUERA, C.; CASTRO, J. Currículo y modernización: cuatro décadas de educación en Colombia. Bogotá: Editorial Magisterio, 2003.

MARTÍNEZ RAMÍREZ, C. D. Reflexiones sobre los retos educativos del Sena. Rutas de Formación: prácticas y experiencias, Bogotá, n. 1, p. 52-57, jul./dez. 2015. Disponível em: <http://revistas.sena.edu.co/index.php/rform/article/ view/229/570>. Acesso em: nov. 2018.

QUIROZ DE ARENA, M. 20 años del Sena en Colombia, 1957-1977. Bogotá: Editorial Presencia, 1978. 
RINCÓN TRUJILLO, H. L. Construyendo aprendizajes en entornos reales de trabajo. Rutas de Formación: prácticas y experiencias, Bogotá, n. 3, p. 82-89, jul./dez. 2016.

SCHUMACHER, E. F. Lo pequeño es hermoso. Barcelona: [s.n.], 1983.

SENA. Unidad Técnica. Acuerdo 12 de 1985. Bogotá, 1985.

SENA. Marco conceptual y pedagógico para la implementación de la formación por proyectos en el Sena. Bogotá, 2007.

SENA. Sistema Integrado de Gestión: documentos institucionales. Bogotá, 2018.

VARGAS PARGA, L. A. Aplicabilidad de la investigación en la formación por proyectos. Rutas de Formación: prácticas y experiencias, Bogotá, n. 2, p. 60-63, jan./jun. 2016.

VELDE, C. An alternative conception of competence: implications for vocational education. Journal of Vocational Education and Training, London, v. 51, n. 3, p. 437-444, 1999. Disponível em: <https://www.tandfonline.com/doi/ abs/10.1080/13636829900200087>. Acesso em: nov. 2018. 